\title{
A Study of Tourism Motivation, Perceived Value and Destination Loyalty for Macao Cultural and Heritage Tourists
}

\author{
Xin Wang ${ }^{1} \&$ Chia Hsin Leou ${ }^{1}$ \\ ${ }^{1}$ Faculty of International Tourism and Management, City University of Macau, Macao \\ Corrspondence: Xin Wang, Faculty of International Tourism and Management, City University of Macau, Macao. \\ E-mail: xwang@cityu.edu.mo
}

Received: August 26, 2015

Accepted: September 17, 2015 Online Published: November 30, 2015

doi:10.5539/ijms.v7n6p83

URL: http://dx.doi.org/10.5539/ijms.v7n6p83

\begin{abstract}
To enhance the understanding of tourists behavior and to provide some suggestions for a sustainable development of cultural and heritage tourism in Macao, data of this study were collected from Macao cultural and heritage tourists who are visiting famous attractions in the historic center of Macao, to observe the tourism motivation, perceived value, and destination loyalty of cultural and heritage tourists in Macao. In this study, the results of factor analysis of cultural and heritage tourism motivation show that tourists' perceived value, which contains three dimensions: scenic value, knowledge value, and social value. These dimensions can be considered as the primary indicators of perceived value which positively influence tourists' destination loyalty. It is worth noting that the direct effect value of cultural and heritage tourism motivation to destination loyalty through perceived value is greater than tourism motivation's direct effect on destination loyalty. Therefore, some suggestions have been put forward for the sustainable development of cultural and heritage tourism in Macao. Firstly, attractiveness cultural heritage in Macao should be designed and highlighted according to tourists' tourism motivation. Secondly, the unique value proposition should be proposed from different dimensions of tourists' perceived value, allowing tourists to experience the differences of Macao from other destinations. Finally, great importance should also be attached to the management of tourists' perceived value other than just continuously increasing the attractiveness of cultural heritage itself based on tourists' tourism motivation, which has an indirect influence on destination loyalty to make publicity for the destination voluntarily of tourists.
\end{abstract}

Keywords: tourism motivation, perceived value, destination loyalty, cultural heritage, Macao

\section{Introduction}

In 2015, Macao embraces the tenth anniversary of successfully declaring the world cultural heritage. Over the past decade, the historic center of Macao has been not only a witness of Macao's historical development, but also one of its important cultural and tourism resources. Macao SAR government, working together with its residents to protect and inherit its cultural heritages, has already achieved some obvious results. Meanwhile, its success in declaring the world cultural heritage has also brought Macao a new opportunity to desalinate its gambling image and develop its diversified tourism.

Tourism motivation, a kind of driving force which drives tourists to meet their different demands, can be considered as the main reason that tourists conduct tourism activities (Iso-Ahola \& Allen, 1982), an subjective factor for tourism demands and the psychological behavior that motivates people to travel (Yang, 2002), and a series of demands urging tourists to participate in a particular tourism activity (Pizam \& Neumann, 1978). Some scholars have made a hierarchical classification of factors of tourism motivation, believing that the main motivation is to relax, to go on a vacation or just to be far away from their daily routine work, followed by other motivations such as contacting with new things, visiting their relatives and friends as well as visiting historical places (Shoemaker, 1989). Others think that there is no primary and secondary relation among tourism motivations which are divided into 6 categories, i.e., psychological factors, emotional factors, personal factors, self-growth factors, status factors and cultural factors (Swarbrook \& Homer, 1999).

The above studies of tourism motivation analyze the reasons for tourism mainly from the perspective of tourists. However, there are some scholars taking the factor of destination attractiveness into consideration when they are studying tourists" behavior and a "push-pull" factor model is consequently formed. On the one hand, "push" factors mainly refer to various factors that motivate individuals' inner demands for traveling; on the other hand, 
“pull” factor merely means tourism destination's attractiveness on tourists (Dann, 1977). Based on this point, some scholars introduce an extended research model in order to have a deep understanding of tourism motivation, bringing forward the cause-and-effect relationship among "push-pull" factors, consumers' tourism satisfaction and destination loyalty. Among them, "push" factors include physical and mental relaxation, social interaction and others; while "pull" factors involve leisure and entertainment at the destination, knowledge learning and so forth; and destination loyalty refers to the willingness of tourists to revisit and recommend it to others (Yoon \& Uysal, 2005).

Tourists' perception will affect to some extent their level of satisfaction, thereby affecting the attractiveness of the destination. Therefore, studies of tourists' perception will provide guidance for the development of cultural and heritage tourism sites. Zeithaml (1988) indicates that perceived value is an overall evaluation made by consumers through weighing their giving and gaining with regard to the product. Petrick (2002) proves that perceived value is an important indicator for repurchasing intention. Some researchers hold that consumers' perceived value includes contents of five dimensions, namely, functional value, epistemic value, emotional value, social value and conditional value. These dimensions affect consumers respectively at the product level and at the purchasing level (Sheth et al, 1991). There are also researchers making a new exposition based on this model. They find that quality and price have different influences on consumers' perceived value and the influences may be negative. Thus, they further divide the consumer functional value into two sub-dimensions: quality value and price value, and then develop a new model. In addition, the dimension of epistemic value is divided into quality value, price value, social value and emotional value (Sweeney et al, 2001). Moreover, good perceived value will not only increase consumers' intention to repurchase, but also make them be willing to recommend the product to others around them.

Researches on consumer loyalty made by foreign scholars are already relatively mature. Enirque (2001) finds that tourism destination image has a significant influence on revisit intention and word-of-mouth publicity of tourist loyalty. Oppermann (2000) thinks that tourist loyalty should be reflected in positive word-of-mouth publicity, recommending behavior and other aspects. At the same time, Jang and Feng (2007) also point out that it is feasible to indicate loyalty by the behavioral tendency to revisit. Based on the above, this study adopts word-of-mouth marketing and revisit intention to define tourist loyalty.

Therefore, the following three hypotheses are proposed on the basis of above literature analyses:

Hypothesis 1: There is a significant positive relationship between tourism motivation and perceived value.

Hypothesis 2: There is a significant positive relationship between tourism motivation and destination loyalty.

Hypothesis 3: There is a significant positive relationship between perceived value and destination loyalty.

\section{Research Design and Method}

\subsection{Scale Structure}

This questionnaire consists of two parts. One is demographics of tourists who visit cultural heritages in Macao, including gender, age, educational level, occupation, monthly income before tax, marital status, nationality and other items; and the other is measurement of tourist motivation, perceived value and destination loyalty. The later part includes 21 items, among which there are 7 items for motivation measurement coming from relevant literature published by Yoon and Uysal (2005) and 12 factors for perceived value by referring to relevant literature published by Sweeney and Soutar (2001). Based on researches made by Oppermann (2000) and Jang et al. (2007), this study adopts word-of-mouth marketing and revisit intention to define tourist loyalty. Subsequently, a 5-point Likert-type scale ( $1=$ strongly disagree, $5=$ strongly agree) was used in the questionnaire.

\subsection{Data Collection}

The old town of Macao, consisting of 22 buildings which are located in Macao peninsula in Macao and 8 adjacent squares and being preserved up to now as "the historic center of Macao" which has witnessed the collision and fusion of Eastern and Western cultures in Macao for more than 400 years, is the center of Macao world cultural heritage resources. Data of this study were collected from Macao cultural and heritage tourists who are visiting famous attractions in the historic center of Macao, such as the Ruins of St. Paul, the Mount Fortress (Macao Museum), Largo do Senado and other 23 world cultural heritage sites. Non-random sampling method is used for investigation during the period from April to May in 2015, with all questionnaires distributed out and returned back both on the spot. This survey involves a total of 514 tourists, and the usable responses were 381 , finally yielding an overall response rate of $74.1 \%$. 


\subsection{Analytical Method}

Excel, Statistical product and service solutions (SPSS) 21.0, and analysis of moment structure (AMOS) 21.0 were used to analyze the data. The analytical method included reliability analysis, validity analysis, confirmatory factor analysis (CFA), and path analysis.

\section{Findings}

\subsection{Demographic Characteristics of the Sample}

In the sample, the proportion of males and females are rather equivalent to each other, accounting for $47.5 \%$ and $52.5 \%$, respectively. The results of this study show that respondents are mainly within the age group of 25-44 years old which accounts for $55.9 \%$, followed by the age group of 18-24 years old and that of 45-59 years old, accounting for $22 \%$ and $16.8 \%$, respectively. In terms of the occupation, the following three types hold a relatively higher proportion, namely, other occupations $(20.7 \%)$, private owners $(15.7 \%)$ and students $(14.2 \%)$. In the sample surveyed in this study, the proportion of tourists from Mainland China is the highest $(75.1 \%)$, followed by Taiwan (10\%) and Hong Kong (7.1\%). As for the educational level, the biggest group among the tourists, accounting for $46.5 \%$, is the one who have achieved their Bachelor degree. In respect of the monthly income before tax, $38.6 \%$ of the tourists earn a monthly income before tax less than MOP 5000 and the tourists who earn a monthly income before tax between MOP 5000 and MOP 10000 rank second, having a proportion of $30.2 \%$.

Table 1. Demographic characteristics of sample $(\mathrm{N}=381)$

\begin{tabular}{|c|c|c|c|}
\hline $\begin{array}{l}\text { Demographic } \\
\text { Characteristics }\end{array}$ & Options & Frequency & $\%$ \\
\hline \multirow[t]{4}{*}{ Age, years } & $18 \sim 24$ & 84 & 22.0 \\
\hline & $25 \sim 44$ & 213 & 55.9 \\
\hline & $45 \sim 59$ & 64 & 16.8 \\
\hline & $\geq 60$ & 20 & 5.2 \\
\hline \multirow[t]{5}{*}{ Source of tourists } & China & 286 & 75.1 \\
\hline & Mainland & 200 & \\
\hline & Hong Kong & 27 & 7.1 \\
\hline & Taiwan & 38 & 10.0 \\
\hline & Other & 30 & 7.9 \\
\hline \multirow[t]{2}{*}{ Marital status } & Married & 197 & 51.7 \\
\hline & Single & 184 & 48.3 \\
\hline \multirow[t]{6}{*}{ Educational level } & Primary school & 6 & 1.6 \\
\hline & Junior middle school & 17 & 4.5 \\
\hline & Senior high school or Technical secondary school & 63 & 16.5 \\
\hline & Junior college & 71 & 18.6 \\
\hline & University or College & 177 & 46.5 \\
\hline & Master or above & 47 & 12.3 \\
\hline \multirow{5}{*}{$\begin{array}{l}\text { Monthly income before tax, } \\
\text { MOP }\end{array}$} & $\leq 5000$ & 147 & 38.6 \\
\hline & $5001 \sim 10000$ & 115 & 30.2 \\
\hline & $10001 \sim 15000$ & 51 & 13.4 \\
\hline & $150001 \sim 20000$ & 28 & 7.3 \\
\hline & $\geq 20000$ & 40 & 10.5 \\
\hline \multirow[t]{10}{*}{ Occupation } & Government staff & 25 & 6.6 \\
\hline & Private owner & 60 & 15.7 \\
\hline & Student & 54 & 14.2 \\
\hline & Clerk & 45 & 11.8 \\
\hline & Teacher & 10 & 2.6 \\
\hline & Worker & 20 & 5.2 \\
\hline & Retiree & 23 & 6.0 \\
\hline & Freelance & 57 & 15.0 \\
\hline & Unemployed & 8 & 2.1 \\
\hline & Other & 79 & 20.7 \\
\hline
\end{tabular}

Note. Macao pataca $=$ US\$1. 


\subsection{Validity and Reliability Analyses of the Sample}

At first, suitability test of the application of factor analysis to the scale is conducted, as shown in Table 2. KMO value of the sample is $0.899(>0.5)$ and the significance probability under Bartlett's test of sphericity is 0.000 $(<0.05)$. The above two values represent that the data are suitable for factor analysis.

Table 2. KMO and results of Bartlett's test of sphericity

\begin{tabular}{lll}
\hline Testing item & & Testing results \\
\hline KMO sample measure & & .899 \\
& Approximate chi-square value & 3742.270 \\
Bartlett's test of sphericity & Degree of freedom & 210 \\
& Significance level & .000 \\
\hline
\end{tabular}

In factor analysis, the common factor is extracted by using the method of principal component extraction and then the method of varimax orthogonal rotation is adopted to rotate the common factor extracted from the questionnaire, and thus the factor loading matrix after rotation is obtained eventually. From the results of the analysis shown in Table 3, we can find that there are 5 common factors which are available to be extracted from these 21 items. And we can also find that the factor loadings for the following 3 factors, that is, "physical and mental relax", "leisure and entertainment" and "good degree of protection for Macao world heritage", are all less than 0.5 , which indicates that these 3 items are not suitable for factor analysis. Therefore, these 3 items are removed so as to improve the results of factor analysis. After the second factor analysis, it shows that the factor loadings of the remaining items are all greater than 0.5. The 5 common factor extracted by using the method of principal component extraction during factor analysis are named respectively "scenic value", "tourism motivation", "destination loyalty", "knowledge value" and "social value". As can be seen from the results of factor analysis, the factor loadings of these 5 common factors are all greater than 0.5 and the accumulated variance contribution rate is $68.835 \%$.

Table 3. Rotating component matrix

\begin{tabular}{|c|c|c|c|c|c|}
\hline Common factor & Item & $\begin{array}{l}\text { Factor } \\
\text { loading }\end{array}$ & $\begin{array}{l}\text { Characteristic } \\
\text { value }\end{array}$ & $\begin{array}{l}\text { Variance } \\
\text { contribution } \\
\text { rate }(\%)\end{array}$ & $\begin{array}{l}\text { Cronbach's } \\
\text { alpha value }\end{array}$ \\
\hline \multirow[t]{7}{*}{ Scenic value } & Tourism experience in line with expectations & .595 & 6.928 & 38.489 & .881 \\
\hline & Fondness of Macao world heritage & .629 & & & \\
\hline & Joyful feelings obtained & .759 & & & \\
\hline & Fantastic tourism experience & .756 & & & \\
\hline & Reasonable entry fees for attractions & .769 & & & \\
\hline & It is worth of spending money on a trip here & .780 & & & \\
\hline & It is worth of spending time on a trip here & .518 & & & \\
\hline \multirow[t]{5}{*}{ Tourism motivation } & To learn historical and cultural knowledge & .793 & 1.966 & 10.923 & .859 \\
\hline & To experience different cultures & .792 & & & \\
\hline & To be more literary and artistic & .775 & & & \\
\hline & $\begin{array}{l}\text { To be infected by the civilization of world } \\
\text { heritage }\end{array}$ & .707 & & & \\
\hline & To travel with one's family and friends & .600 & & & \\
\hline \multirow[t]{2}{*}{ Destination loyalty } & $\mathrm{He} /$ she will revisit here & .848 & 1.344 & 7.468 & .819 \\
\hline & $\begin{array}{l}\mathrm{He} / \text { she will recommend it to relatives, friends } \\
\text { and colleagues }\end{array}$ & .830 & & & \\
\hline \multirow[t]{3}{*}{ Knowledge value } & $\begin{array}{l}\text { It makes others feel a breath of "literary and } \\
\text { artistic youth" }\end{array}$ & .804 & 1.110 & 6.166 & 686 \\
\hline & It makes others have a different look & .799 & & & \\
\hline & $\begin{array}{l}\text { It is no use increasing the experience by free } \\
\text { attractions }\end{array}$ & .721 & & & \\
\hline Social value & It can be a topic of conversations with others & .927 & 1.042 & 5.789 & \\
\hline
\end{tabular}

Note. Principal component analysis adopts Kaiser standardized orthogonal rotation method. And it is converged after 5 iterations. Factor loadings which are less than 0.5 are removed. 
As shown in the above Table 3, cultural and heritage tourism motivation mainly includes 5 factors: to learn historical and cultural knowledge (M1), to experience different cultures (M2), to be more literary and artistic (M3), to be infected by the civilization of world heritage (M4) and to travel with one's family and friends (M5).

The results of factor analysis show that tourists' perceived value includes scenic value (PV1), knowledge value (PV2) and social value (PV3). In this study, these 3 dimensions are considered as the primary indicators (latent variables) of perceived value and the corresponding observational items of these 3 dimensions are regarded as the secondary indicators (observed variables). Specifically, scenic value has 7 observational items: tourism experience in line with expectations (V1), fondness of Macao world heritage (V2), joyful feelings obtained (V3), fantastic tourism experience (V4), reasonable entry fees for attractions (V5), it is worth of spending money on a trip here (V6), and it is worth of spending time on a trip here (V7); knowledge value involves 3 observational items, including it makes others feel a breath of "literary and artistic youth" (V8), it makes others have a different look (V9) and it is no use increasing the experience by free attractions (V10); and social value corresponds to the only observational item, it can be a topic of conversations with others (V11).

Destination loyalty consists of two factors: he/she will revisit here (DL1) and he/she will recommend it to relatives, friends and colleagues (DL2).

\subsection{Path Analysis and Hypothesis Test}

The research model constructs 3 structural variables, proposes conceptual models and hypothesis on respectively constructed latitudes of tourist motivation for culture heritages, perceived value, destination loyalty, and the relationships among the three, imports the data into software AMOS21.0 to calculate, and uses maximum likelihood estimation to estimate the hypothesis models. In the gained output models, AGFI (Adjusted goodness-of-fit index) and RFI (Relative Fit Index) are lower than the range of critical value(more than 0.9), therefore further correction of the models is needed to reduce chi-square measure by releasing more parameters, improve the fitness of models, and obtain superior models(see Table 4).

Table 4. Contrast of the overall goodness of fit before and after model correction

\begin{tabular}{|c|c|c|c|c|c|c|c|c|c|}
\hline & $\begin{array}{l}X^{2} / \text { Degrees } \\
\text { of freedom }\end{array}$ & $\begin{array}{l}\text { Root Mean Square } \\
\text { Error of } \\
\text { Approximation } \\
\text { (RMSEA) }\end{array}$ & $\begin{array}{l}\text { Goodness-of-fit } \\
\text { index } \\
\text { (GFI) }\end{array}$ & $\begin{array}{l}\text { Adjusted } \\
\text { goodness-of-fit } \\
\text { index } \\
\text { (AGFI) } \\
\end{array}$ & $\begin{array}{l}\text { Normed fit } \\
\text { index } \\
(\mathrm{NFI})\end{array}$ & $\begin{array}{l}\text { Relative fit } \\
\text { index } \\
\text { (RFI) }\end{array}$ & $\begin{array}{l}\text { Incremental } \\
\text { fit } \\
\text { index } \\
\text { (IFI) } \\
\end{array}$ & $\begin{array}{l}\text { Tucker-Lewis } \\
\text { index } \\
\text { (TLI) }\end{array}$ & $\begin{array}{l}\text { Comparative } \\
\text { fit } \\
\text { index } \\
\text { (CFI) } \\
\end{array}$ \\
\hline $\begin{array}{l}\text { Fit criteria } \\
\text { or critical } \\
\text { value }\end{array}$ & $<2.0$ & $\begin{array}{l}<0.8 \text { Well; } \\
<0.5 \text { Excellent }\end{array}$ & $>9.0$ & $>9.0$ & $>9.0$ & $>9.0$ & $>9.0$ & $>9.0$ & $>9.0$ \\
\hline $\begin{array}{l}\text { Initial } \\
\text { model }\end{array}$ & 2.793 & 0.073 & 0.979 & 0.779 & 0.915 & 0.889 & 0.958 & 0.965 & 0.913 \\
\hline $\begin{array}{l}\text { Corrected } \\
\text { model }\end{array}$ & 1.941 & 0.047 & 0.987 & 0.902 & 0.933 & 0.932 & 0.989 & 0.977 & 0.946 \\
\hline
\end{tabular}

The model is obtained after the correction according to the correction indicators, as shown in Figure 1 below: 


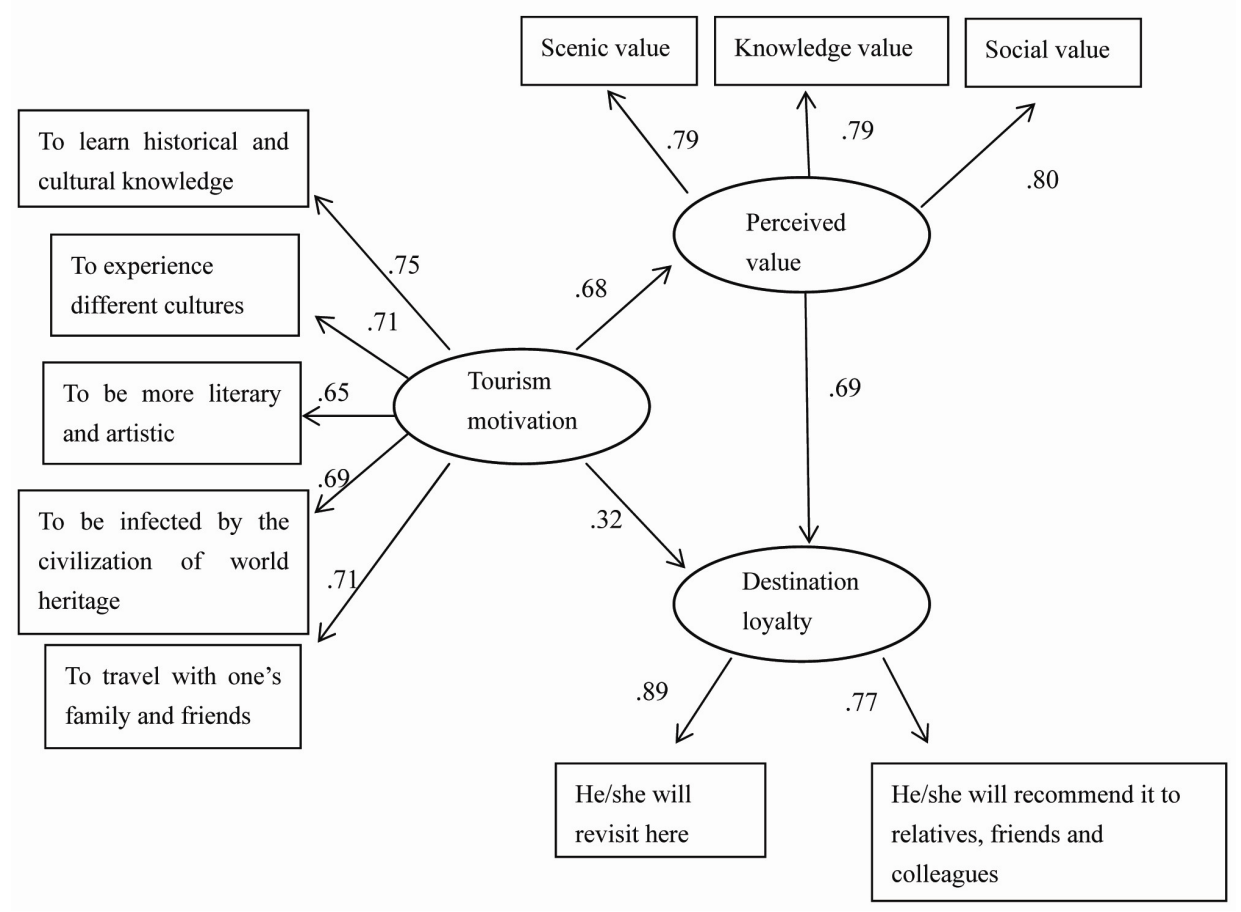

Figure 1. Model diagram (after correction)

As can be seen from the corrected model, all the indicators conform to the test standards, which suggests that the actual data and the theoretical model matches with each other very well. Among these data, the standardized path coefficient of cultural heritage tourism motivation to perceived value and destination loyalty are 0.676 and 0.323 , respectively; and the standardized path coefficient of cultural heritage tourists' perceived value to destination loyalty is 0.692 . In addition, the regression coefficients of these five motivation factors concerning cultural heritage tourism motivation are all significant; the standardized regression coefficients of factors that are relevant to cultural heritage tourists' perceived value are $0.789,0.791$ and 0.798 , respectively; and the regression coefficients of the two correspondent basic variables of destination loyalty also reach the significant level (See Table 5).

Table 5. Path coefficients of the corrected structural model

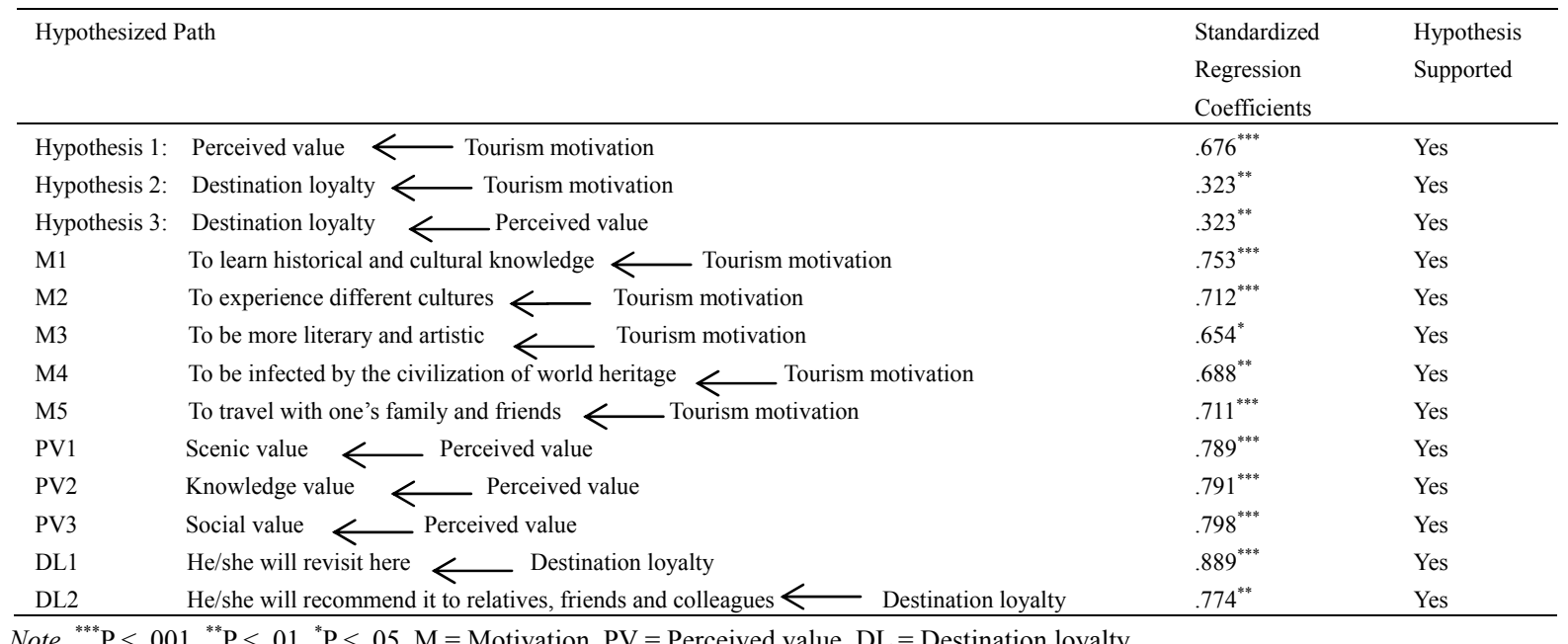


To sum up, the following conclusions can be drawn from the test of the three hypotheses mentioned above:

Hypothesis 1 proposes that there is a significant positive relationship between cultural and heritage tourism motivation and perceived value. The results fully support this hypothesis with the path coefficient of 0.676 and the p-value less than 0.001 , which indicates that cultural and heritage tourism motivation positively affects perceived value under the significant level of 0.001 .

Hypothesis 2 assumes that there is a significant positive relationship between cultural and heritage tourism motivation and destination loyalty. This hypothesis is fully support with the path coefficient of 0.323 and the p-value less than 0.01 , which suggests that cultural and heritage tourism motivation positively affects destination loyalty under the significant level of 0.01 .

Hypothesis 3 predicts that there is a significant positive relationship between perceived value and destination loyalty. The results fully support this hypothesis with the path coefficient of 0.692 and the p-value less than 0.001 , which shows that perceived value positively affects destination loyalty under the significant level of 0.001 .

It is worth noting that the direct effect value of cultural and heritage tourism motivation to destination loyalty is 0.323 while the indirect effect value is $0.468\left(0.676^{*} 0.692\right)$, leading to a total effect value of 0.791 .

\section{Conclusions and Suggestions}

This study, setting Macao cultural and heritage tourists who are on their trip as the sample, analyzes the tourists' tourism motivation and their perceived value by using the method of questionnaire, and also identifies the relationships among tourism motivation, perceived value and destination loyalty, aiming to help cultural and heritage destinations adopt corresponding marketing strategies in accordance with different segment markets, attract tourists to revisit and achieve word-of-mouth marketing for destinations and to provide a reference for further studies of the field of tourist destination loyalty as well. Through an empirical study, main conclusions of this study can be made as follows. In the first place, the main tourism motivation of Macao cultural and heritage tourists is subdivided through an investigation on tourists' tourism motivations. To learn historical and cultural knowledge, to experience different cultures, to be literary and artistic, to know about the world civilization and to travel with their relatives and friends are all important motivations that attract and urge tourists to enjoy their cultural and heritage tourism in Macao. Next, the dimensions of perceived value of Macao cultural and heritage tourism are determined accordingly. Furthermore, this study also finds that perceived value of Macao cultural and heritage tourism is multi-dimensional, scenic value, knowledge value and social value included. The analysis of perceived value and its dimensions can provide guidance for the creation, transfer and delivery of tourism value, thus creating destination value corresponding to tourists' demands. Then, this study verifies the relationship among motivation, perceived value and destination loyalty. Concretely speaking, the stronger the cultural and heritage tourism motivation is, the higher the perceived value obtained by the tourists can be and the more loyal to the destination the tourists are. Tourist loyalty mainly reflects in the improvement of revisit intention and their willingness to make word-of-mouth marketing for the destination voluntarily. What's more, this study also finds that the indirect effect of cultural and heritage tourism motivation on destination loyalty through perceived value is greater than tourism motivation's direct effect on destination loyalty. As a result, the mediating effect of perceived value should be paid enough attention to during the development process of Macao cultural and heritage tourism instead of enhancing destination loyalty merely depending on the stimulation of tourists' tourism motivation.

On the whole, there are several suggestions of this study that are put forward for the sustainable development of Macao cultural and heritage tourism.

Firstly, attractiveness of Macao cultural heritage should be designed and highlighted according to tourists' tourism motivation. To start with, the function of historical and cultural knowledge learning of Macao cultural heritage should be stressed. Sufficient publicity of the connotation, history and culture of heritage by setting cultural heritage itself as a medium to impart knowledge can trigger tourists' thoughts and reflections through their knowledge about and contact with the "thing", thus further stimulating their desire for knowledge and then seeking for an in-depth understanding of heritage tourism attractions. Then, enough attention should be paid to the experiential factors of cultural and heritage tourism. Many means, such as sound, light and shadow, images, texts and others can be used to create a different cultural heritage tourism experience for tourists coming to visit in Macao. For example, the activity of "light and shadow of Ruins of St.Paul" during Macao Arts Festival, using original music accompanied with advanced image projecting techniques, plays video images on the outer wall of the Ruins of St.Paul, applying cinematographic art into the world heritage architecture and telling stories in the acoustic shadow, finally allowing tourists to experience the different kind of charm of cultural heritage. Finally, 
supporting services of Macao world heritage sites should be perfected, such as adding guidelines to scenic spots, free guides, etc. These services can make it convenient for tourists to visit and know about the cultural heritage. At the same time, supporting facilities, such as nursery rooms, special channels for disabled tourists, braille guide and so forth, should also be improved, providing convenience for tourists to travel with relatives and friends of different ages or different needs.

Secondly, its "unique value proposition" should be highlighted from various kinds of aspects such as scenic spot planning, route design, product development and so on during the sustainable development process of Macao cultural and heritage tourism, allowing tourists to experience the differences of Macao from other places. As for tourism consumers, capturing value is a key factor for them to make their tourism decisions. Thus, tourism experience in accordance with tourists' motivation can be created through scenic value, knowledge value, social value, etc. In the process of such kind of experience, tourists can gain aesthetic pleasure during their sightseeing, experience the colorful life by contacting with others, realize and improve oneself through active imitation of other roles in their life, and enjoy common happiness when expending money and time during their trip. What's more, differentiated marketing strategies are applied to this kind of experience. For instance, promotion is made with the help of mobile terminals under the network economic era so as to stimulate tourists coming to visit Macao world heritage sites to use free WiFi to take photos and "clock in and out" and to share their position location or text and image information, etc so that other individuals in their social network are able to receive this kind of information, which will, in turn, achieve the precise point-to-point marketing of Macao world cultural and heritage tourism destination.

Finally, the effect of cultural and heritage tourism motivation on destination loyalty through the mediating effect of perceived value is greater than cultural and heritage tourism motivation's direct effect on destination loyalty. Therefore, great importance should also be attached to the management of tourists' perceived value other than just continuously increasing the attractiveness of Macao cultural heritage itself based on tourists' tourism motivation. The unique value proposition of Macao cultural and heritage tourism should be proposed from different dimensions of tourists' perceived value. In view to the fact that tourism motivation has an indirect influence on destination loyalty via perceived value, positive revisit intention and willingness to make word-of-mouth publicity for the destination voluntarily of tourists should be well guided to keep the sustainable development of Macao cultural and heritage tourism.

\section{References}

Dann, G. M. (1977). Anomie, ego-enhancement and tourism. Annals of tourism research, 4(4), 184-194. http://dx.doi.org/10.1016/0160-7383(77)90037-8

Enrique, J. B., Isabel, M. S., \& Javier, S. T. (2001). Tourism Image, Evaluation Variables and after Purchase Behavior: Interrelationship. Tourism Management, 22(6), 607-616. http://dx.doi.org/10.1016/S0261-5177(01)00035-8

Iso-Ahola, S. E., \& Allen, J. R. (1982). The dynamics of leisure motivation: The effects of outcome on leisure needs. Research Quarterly for Exercise and Sport, 53(2), 141-149. http://dx.doi.org/10.1080/02701367.1982.10605240

Jang, S. C., \& Feng, R. M. (2007). Temporal Destination Revisit Intention: The Effects of Novelty Seeking and Satisfaction. Tourism Management, 28(3), 580-590. http://dx.doi.org/10.1016/j.tourman.2006.04.024

Oppermann, M. (2000). Tourism destination loyalty. Journal of Travel Research, 39(1), 78-84. http://dx.doi.org/10.1177/004728750003900110

Petrick, J. F. (2004). The roles of quality, value, and satisfaction in predicting cruise passengers behavioral intentions. Journal of Travel Research, 42(4), 397-407. http://dx.doi.org/10.1177/0047287504263037

Pizam, A., Neumann, Y., \& Reichel, A. (1978). Dimentions of tourist satisfaction with a destination area. Annals of tourism Research, 5(3), 314-322. http://dx.doi.org/10.1016/0160-7383(78)90115-9

Sheth et al. (1991). Customer Orientation: Effects on Customer Service Perceptions and Outcome Behaviors. Journal of Service Research, 3(3), 241-251.

Swarbrooke, J., \& Horner, S. (2007). Consumer behaviour in tourism. London, England: Routledge.

Sweeney, J. C., \& Soutar, G. N. (2001). Consumer Perceived Value: The Development of Multiple Item Scale. Journal of Retailing, 1(11), 203-220. http://dx.doi.org/10.1016/S0022-4359(01)00041-0

Yoon, Y., \& Uysal, M. (2005). An examination of the effects of motivation and satisfaction on destination loyalty: a structural model. Tourism management, 26(1), 45-56. http://dx.doi.org/10.1016/j.tourman.2003.08.016 
Zeithaml, V. A. (1988). Consumer perceptions of price, quality and value: A means-end model and synthesis of evidence. Journal of Marketing, 52(3), 2-22. http://dx.doi.org/10.2307/1251446

\section{Copyrights}

Copyright for this article is retained by the author(s), with first publication rights granted to the journal.

This is an open-access article distributed under the terms and conditions of the Creative Commons Attribution license (http://creativecommons.org/licenses/by/3.0/). 